\title{
أثر النسيج المسسم فى رفع مستوى التوافق \\ لاطفال المؤسسات الايوائية
}

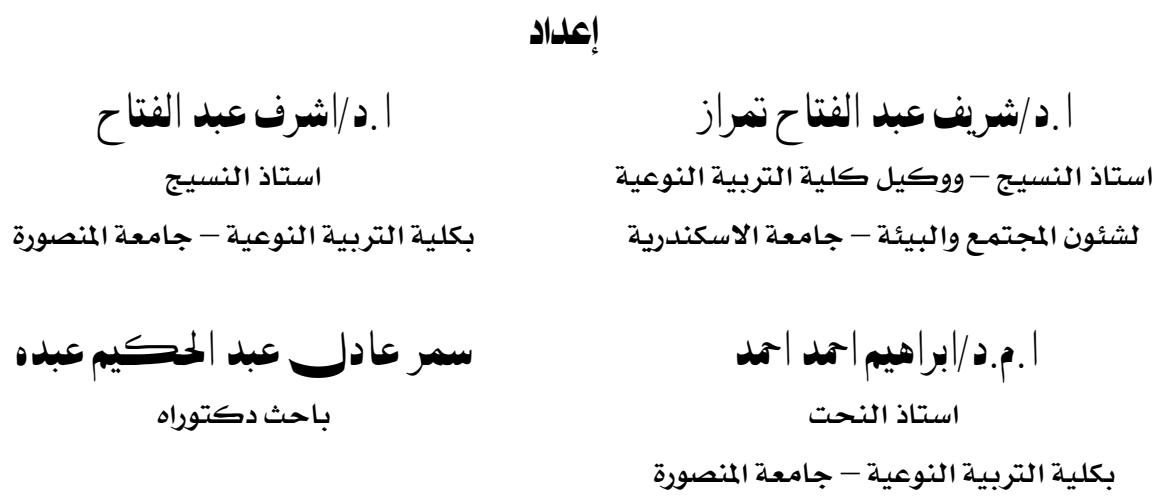

مجلة بحوث التربية النوعية ـ جامعة المنصورة

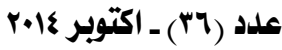




\title{
أثر النسيج المسسم فى رفع مستوى التوافق لاطفال المؤسسات الايوائية
}

\author{
إعداد

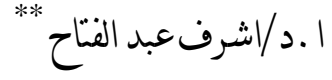 \\ سمر عادل عبد الحكيم عبده

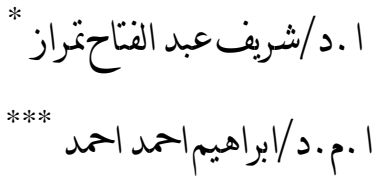

المضص البحث:

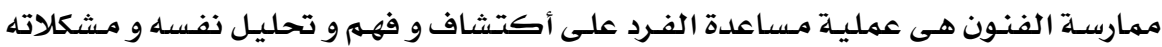

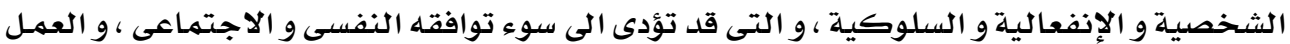

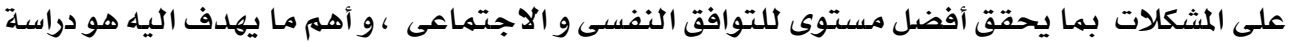
شخصية الفرد حتى يهكنه توجيه حياته بافضل طريقة ممكنه

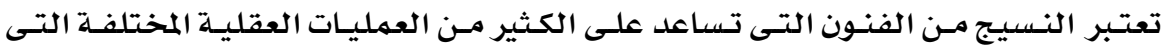
تساعد الاطفال اصحاب سوء التوافق النفسى و الاجتماعى على تحسينهم . و من هنا ترى الباحثة اهمية بناء برنامج فنى لتوظيف النسيج فى حيـاة اطفـال المؤسسات ،

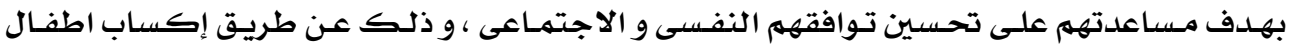

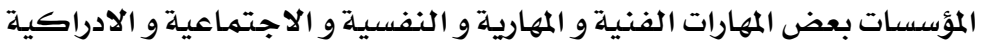

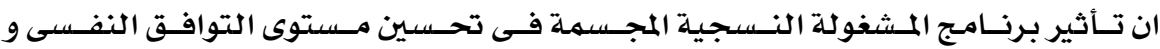

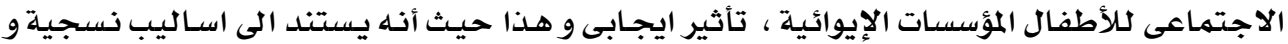

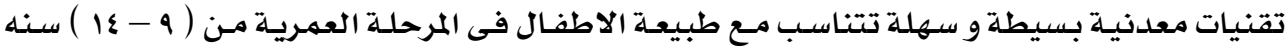

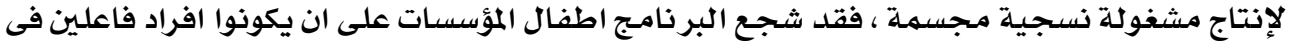

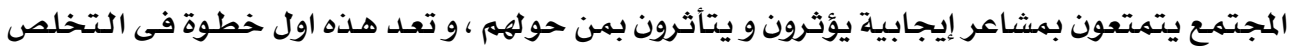

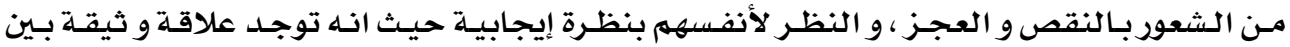

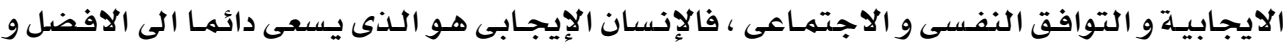

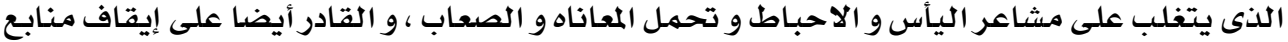

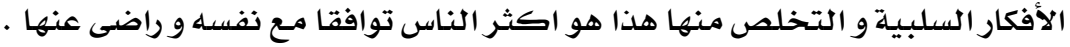




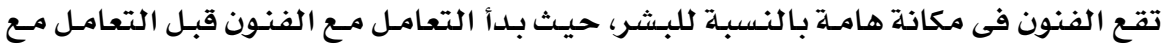

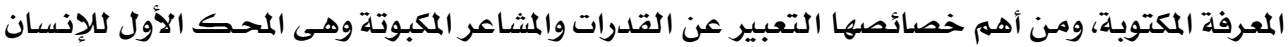

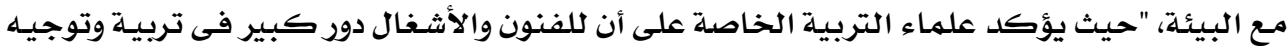

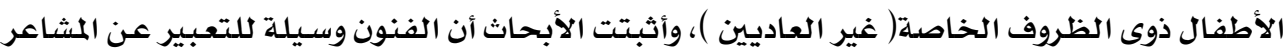

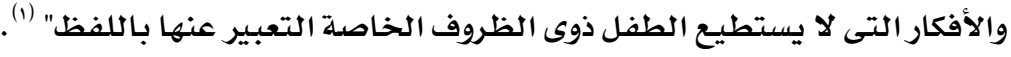

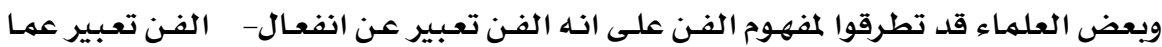

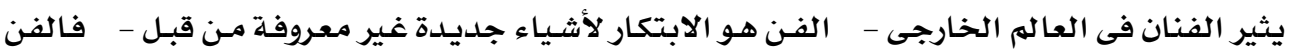

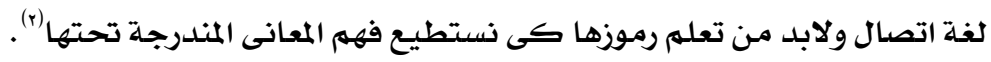

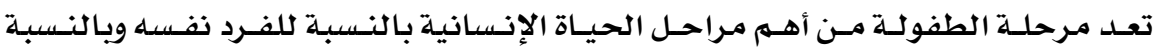

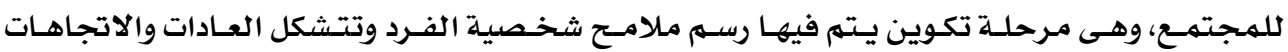

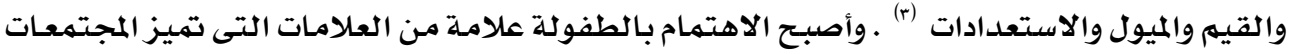

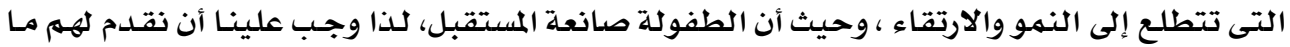

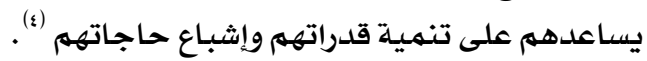

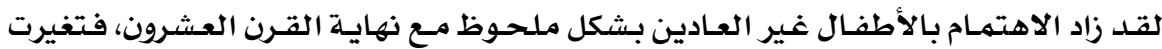

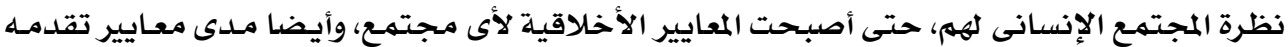

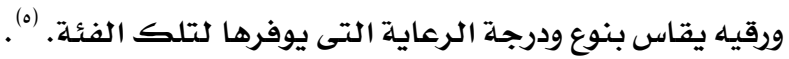
ولكن قد نجـد أطفالا قست عليهم الظـروف وحرمـوا مـن النشأة فى بيئـة أسـرهم الطبيعيـة نظرا لظروف تستدعى ذلك مثل: ا ـ الحرمان من أحد الوالدين أو كليهما.

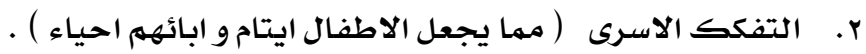
r. مرض العائل لفترة طويلة بمرض مزرمن.

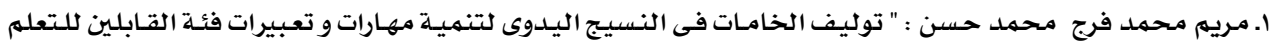

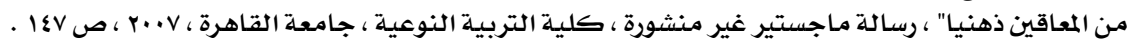

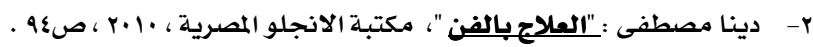

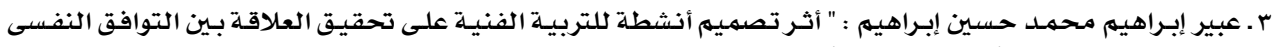

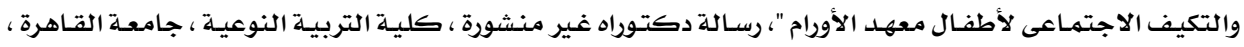

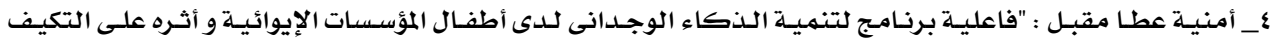

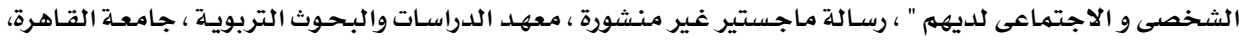
ه - عايدة عبد الحميد محمـد ابو القطط : "التربيـة الفنيـة للأطفال غير العـاديين"، حورس للطباعة و النشر، بـدون

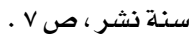




$$
\text { ؟. }
$$

وهؤلاء الأطفال مهن حرموا من الرعايـة الأسريـة الطبيعية، وأودعوا فى المؤسسسات الإيوائيسة

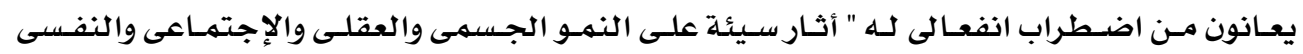
للطفل، حيث يؤثر على إقامـة علاقات سوية للطفل مـ الآخرين وحدوث أكبر مشاكل السول السلوك مثل المخاوف والقلق (2).

يلعسب التوافق دورا هامـا فى أداء الفـرد و إنتاجسه، ذلـك لأن الأفراد الـذين يعـانون مـن سـوء

التوافق تتبـد طاقاتهم، ولا يسـتطيعون التركيز فى أى عمل مـا سـواء كـان عمـلا دراسـيا أو إنتاجيـا، ومـن ثم فإنهم في حاجـة مـاسـة الى مسساعدتهم على التغلـب أو التخلص مهـا يعـانون مـن سـوء التوافق

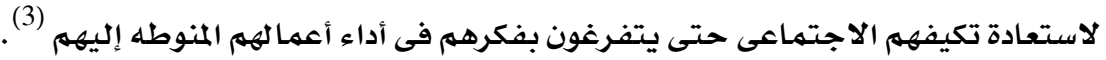

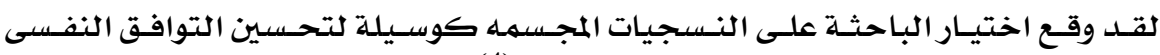

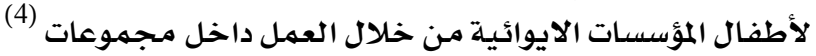
ومفهـوم النشـاط داخـل إطـار ميــان التربيـة الفنيـة ينقسهم الى شـقين : الشقى الأول يـرتبط بهمارسـة الفن، أما الشق الثانى فيرتبط بتوظيف التربية الفنية فى خدمـة المجتهـع (1). ومن جـانب أخر هناك دور هام لممارسـة النشاط الفنى وهو مسـاعدة الطفل على الإفصـاح عن مشاعره وانفعالاته، كما أن مهارسسة الأنشطة الفنيـة تنعكس على حالثة الطفل النفسية والاجتمهاعيـة

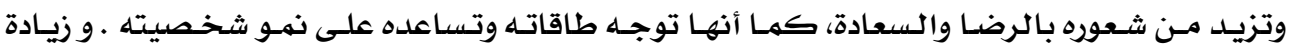

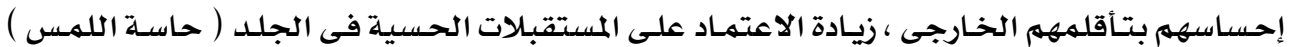
والعضلات و المفاصل ليفرغ طاقته فى عمل أشكال مختلفة .

و يمكن أن نجذب نظر الطفل محل الدراسة للفن مـن خلالال التشكيلات النسسجية المجسمهة

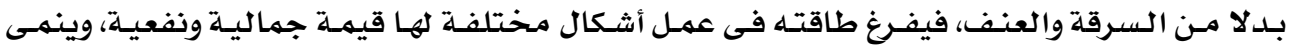
ذكائه فى نفس الوقت، وبالتا لى تكون الفرصسة سـانحة لـه لكى يكتسب خـبر ات مهاريـة يهكن أن تكون

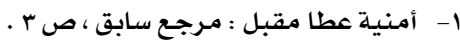

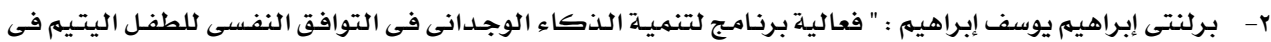

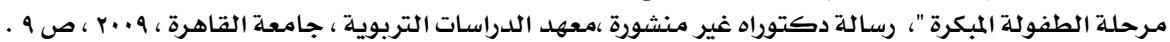

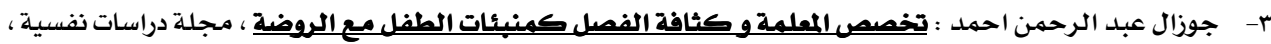

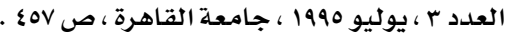

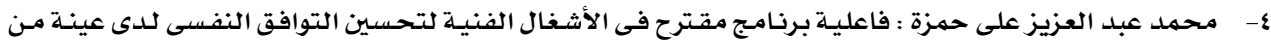

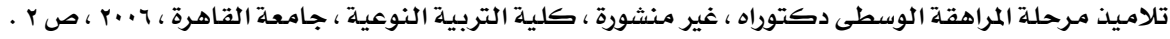
ا - ياسر محمد فوزى : " برنامج مقترح من أنشطة التربية الفنية لتنمية الاتجاه الإيجابي نحو القراءة للأطفال" ، رسالة

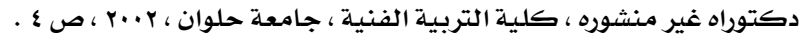




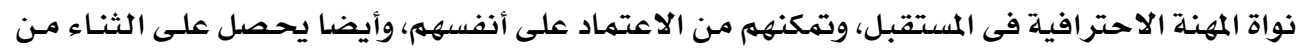

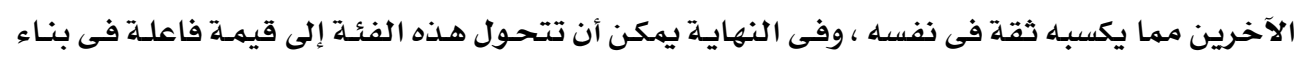

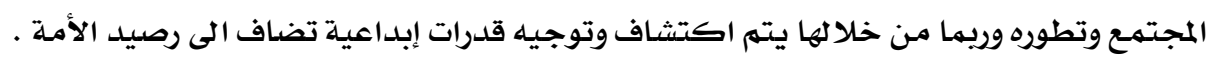

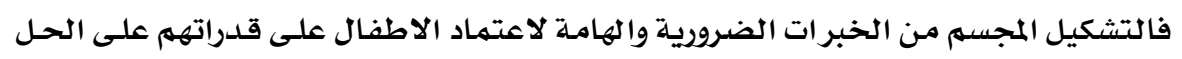

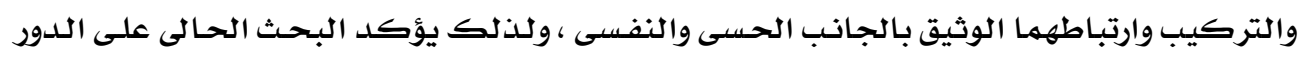

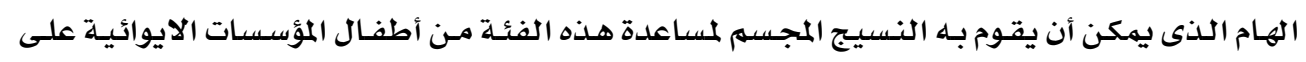

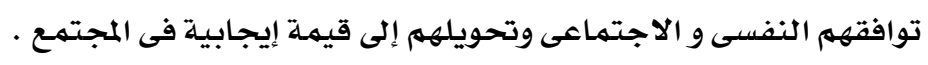

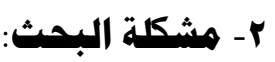

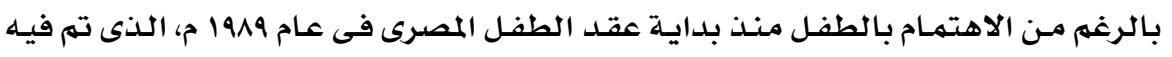

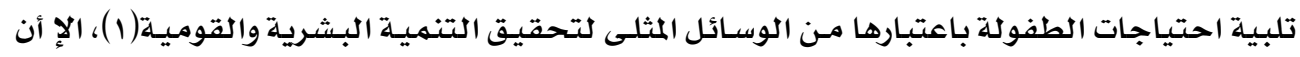

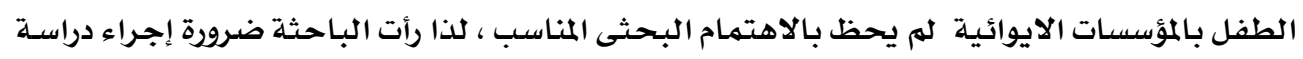

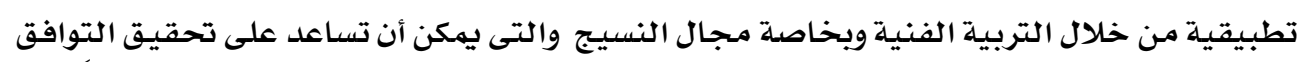

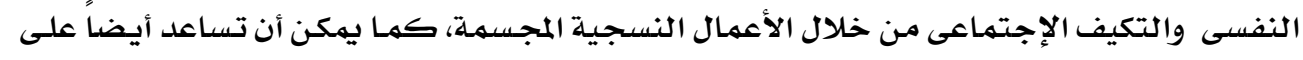

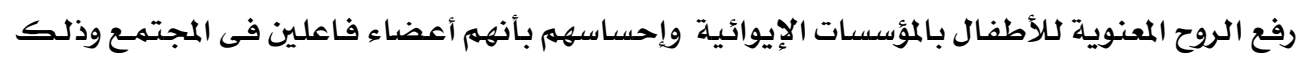
من خلال برنامـج للنسيج المجسيم.

\section{ويمكن إجمال مشكلة البحث فى التساؤل التالي :}

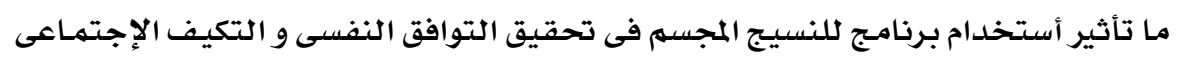

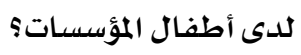

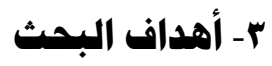

(أ) التعرف على بعض الجوانب النفسية والاجتماعية التى يعانى منها الأطفال بالمؤسسات الايوائية.

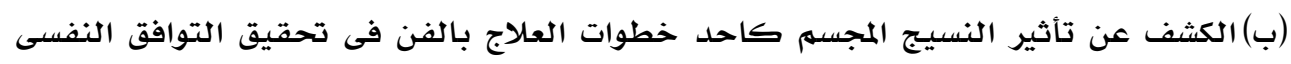

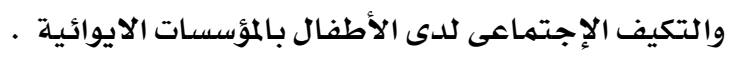

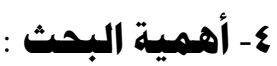

تكمن أهمية البحث فى ارتباطـه بـالمجتمع وخاصـة الأطفـال نزلاء المؤسسـات الإيوائيسة ، ولأن

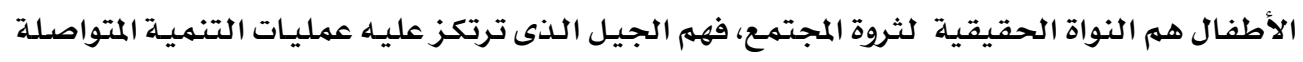

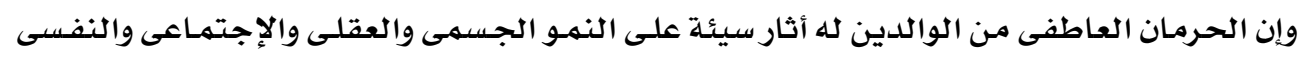

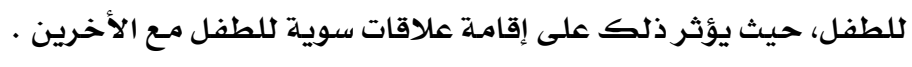

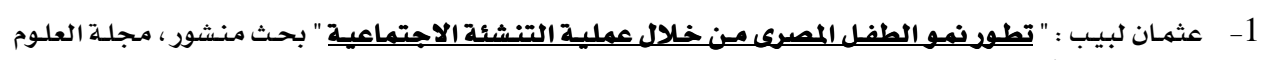

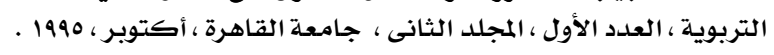




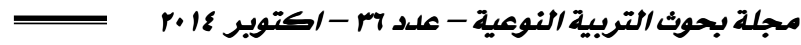

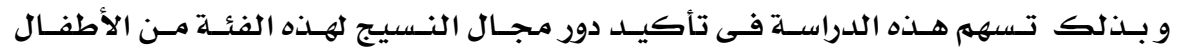

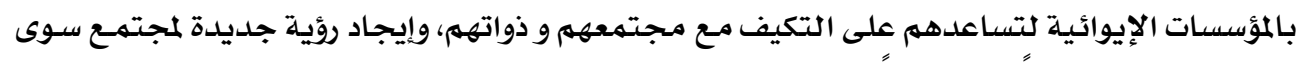

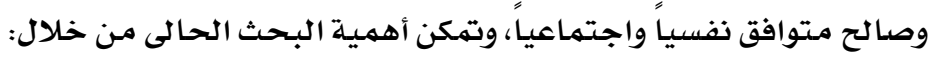

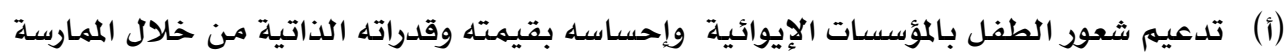

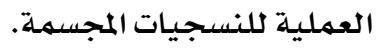

(ب) تأكيد دور فن النسيج المجسم فى بناء الشخصية و التغلب على المشكلات طفل

$$
\text { المؤسسات الإيوائية. }
$$

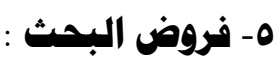

\section{تتبنى الدراسة الحالية الفروض التالية :}

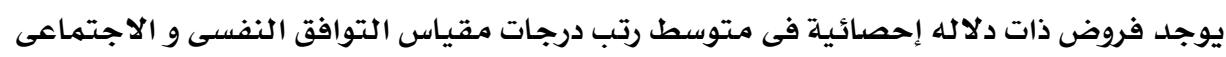

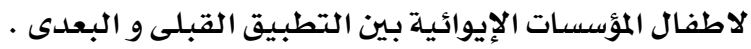

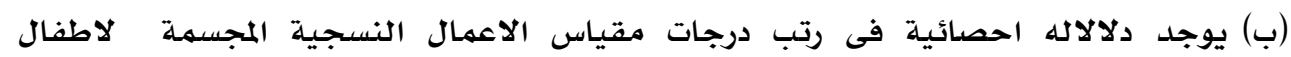

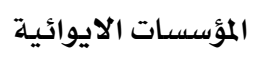

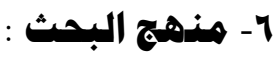

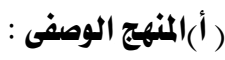

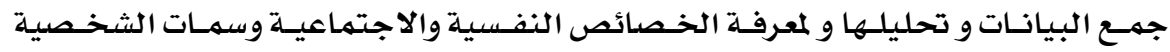

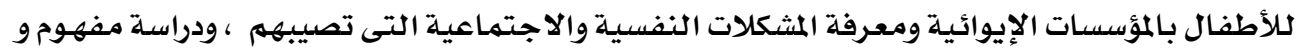

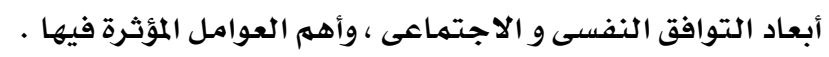

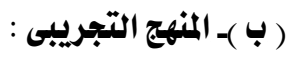

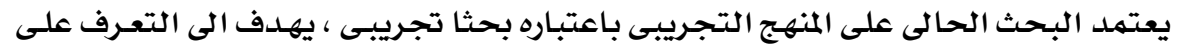

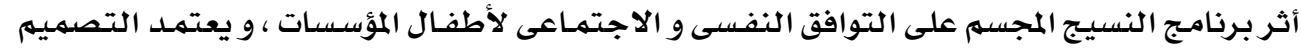

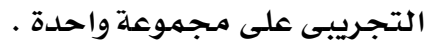

- خطة البحث:

أولاً : الإطار النظرى :

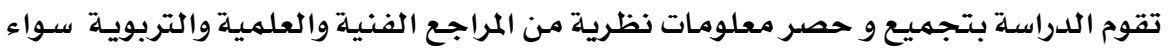

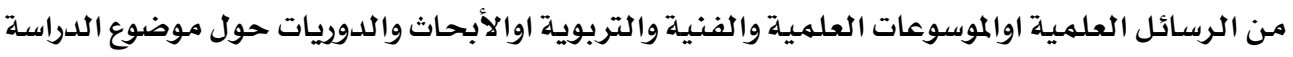

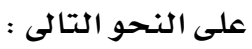


(أ) دراسة تحليلية لمعرفة الخصائص النفسية والاجتماعية وسمات الشخصية للأطفال بالمؤسسات

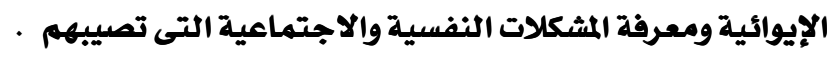

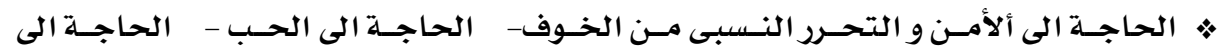

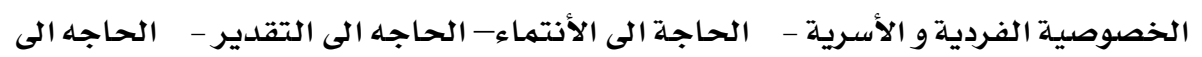

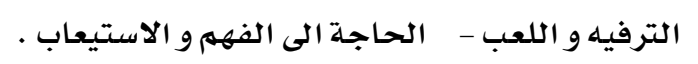

• و بعض السمات مثل :سمة الشعور بالإثم - سمة الخجل و الأنطواء سمة الخيال و التوتر

(ب) دراسة مفهوم و أبعاد التوافق النفسى و الاجتماعى ، وأهم ا لعوامل المؤثرة فيها .

• التوافق النفسى يركز على الجوانب النفسية للفـرد حيـث ان كل فرد لـه مطالب نفسية

خاصة بهـراحل نهوه المختلفة.

- من خلال التوافق النفسى يحدث انسجام و اتزان بين حاجات الفرد و متطلبات البيئة .

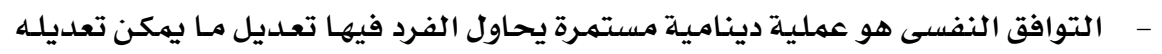

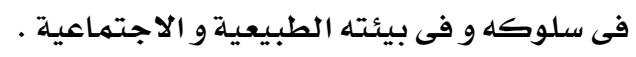

- التوافق النفسى هو شعور الفرد بالسعادة و الرضا عن النفس واحداث نوع من التوازن و

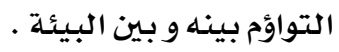

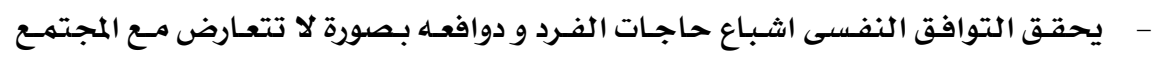

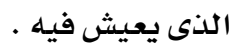

* ابعاد التوافق النفسى ( التوافق الشخصى - التوافق الاجتماعى )

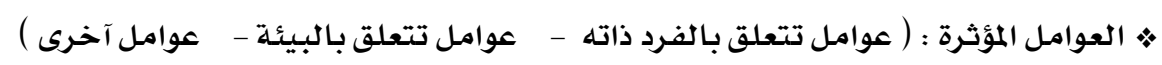

(ج) تحليل دور تشكيلات النسيج المجسم فى تحقيق التوافق النفسى و الاجتماعي لدى الأطفال

بالمؤسسات الايوائية.

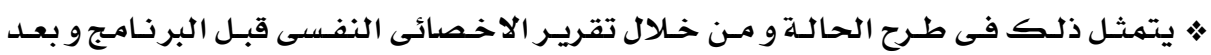

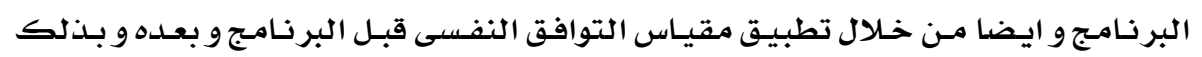

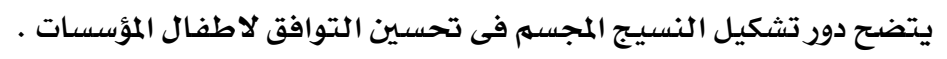

(د) دراسة لأسلوب النسيج المجسم والمرتبطة بالتنفيذ العملى لعينة الدراسة وطرق تنفيذها بهدف

التوصل لمداخل جديدة تفيد مجتمع الدراسة من الأطفال بالمؤسسات الإيوائية.

• مثل دراسـة الخامـات النسـجية - التقنيـات النسـجية البسسيطة - التعـرف على الاسـلاك

المعدنية و كيفة تشكيلها و تجسيهها

(ه) دراسة وصفية تحليلية للدراسات السابقة المرتبطة بموضوع الدراسة . 
بناء على نتائج الإطار النظرى سوف تقوم الدارسـة بإجراء بعض التطبيقـات العمليـة بهـدف

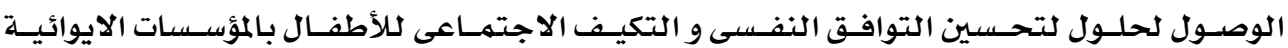
من خلال :

(اختيار عينة البحث من الأطفال بالمؤسسات الايوائية من سن ( ه - عا ) ) سنة من بعض مؤسسات

$$
\text { دور الرعاية . }
$$

(ب) قياس قبلى للتوافق النفسى و التكيف الأجتماعى للأطفال عينة الدراسة. (ج) عمل تجارب تطبيقية للأعمال النسجية المجسمة المنتجة من من أعمال الأطفال بالمؤسسات الإيوائية.

(د) قياس بعدى لقياس التوافق النفسى و الإجتهماعى للأطفال محل الدراسة.

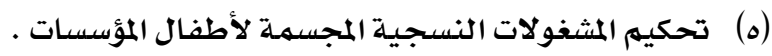
(و) تحليل ما سيتم التوصل اليه من نتائج للتحقق من فروض البحث.

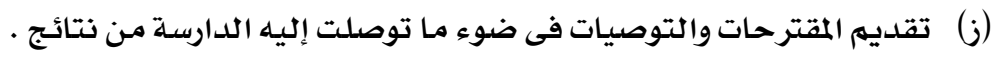

\section{الغطولات الاجرائيه للبمث :-}

عينه البحث :- تقوم الباحثه بلدراسـه استقسائيه للاطفال ِِّ دور الايـواء المختلفـه لاجـراء استبيان وتقصي لحالتهم مِ حدود ه أطفال 1 - مدود البمث : n

\section{تتمثل حدود الدراسة فيما يلى :}

1- يقتصر البحث على المجسمات النسجية r- ينتهى أفراد العينـة لأطفال المؤسسات الإيوائية بمحافظة الإسكندريـة.

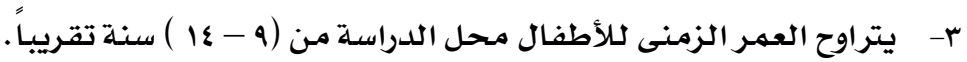
-

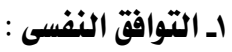

يعرف " محمد محمد الشيخ " التوافق النفسى بأنه عمـل إيجـابى مستمـر يحساول الفـرد مـن

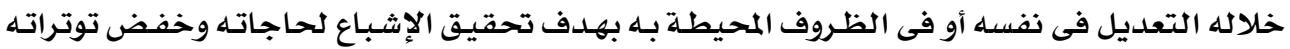
والتوازن والانسجام مـع بيئتته . 


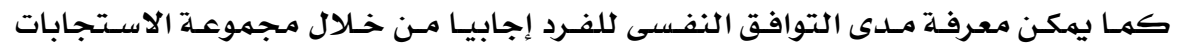

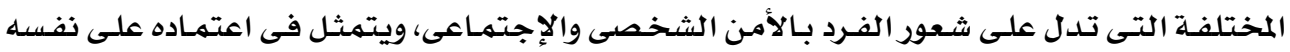

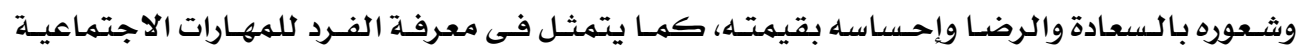

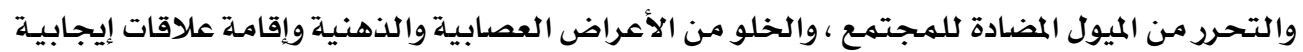

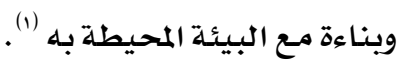

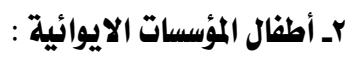

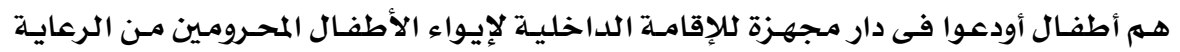

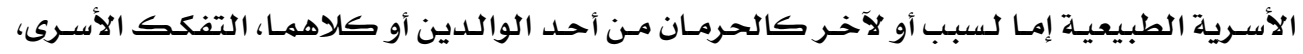

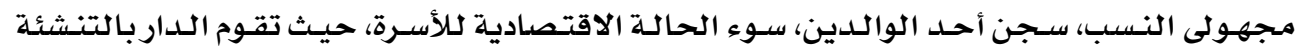

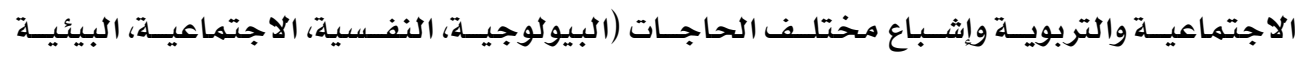

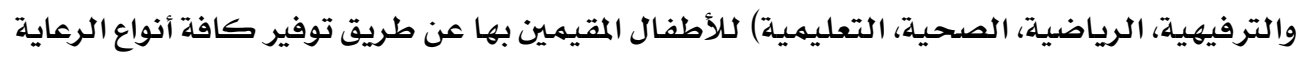

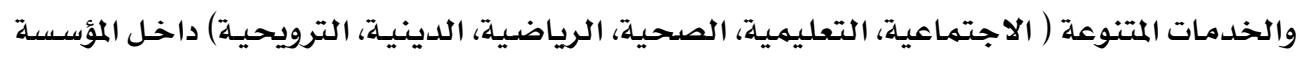

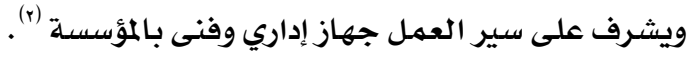

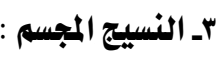

مسن الإتجاهـات التشكيلية المستحدثة في فن النسجيات اليدويـة هـو فن النسيج المجسسمر ،

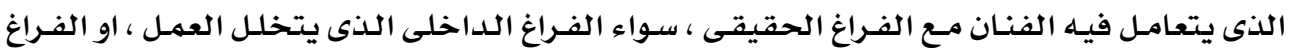

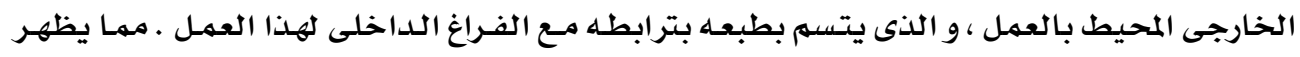

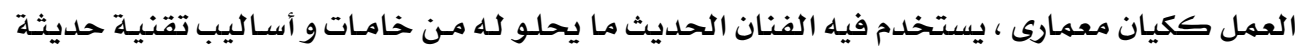

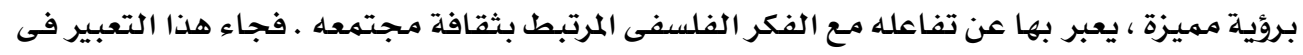

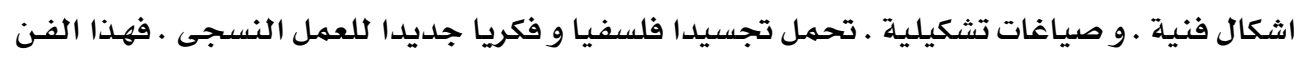

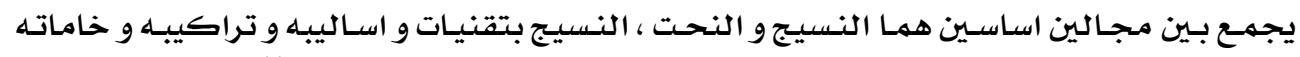

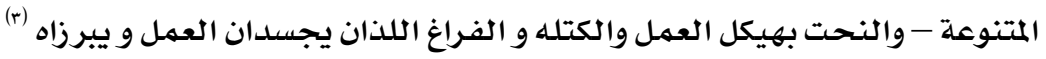

\section{عرض و توصيف التجربة البحثية}

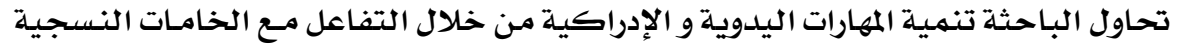

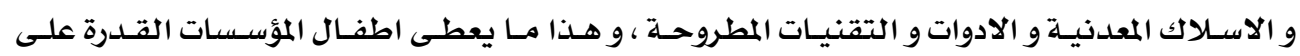

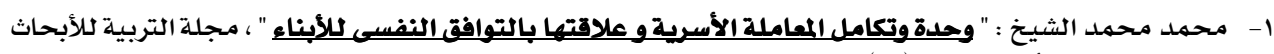

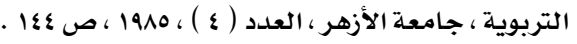

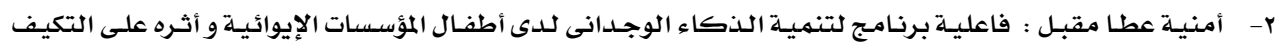

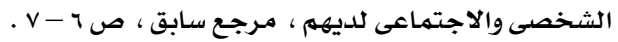

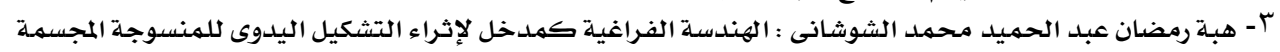

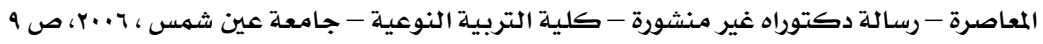




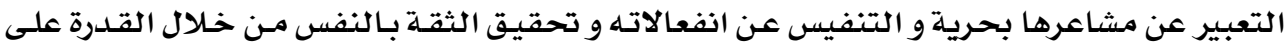

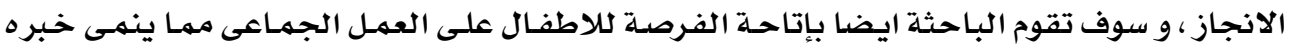

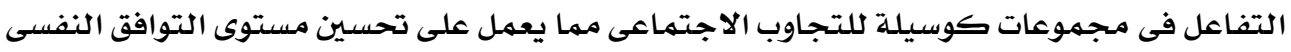

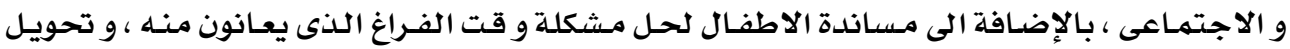

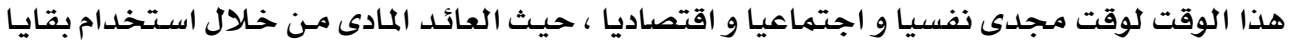

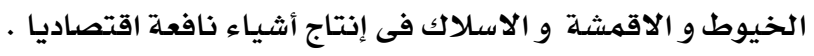

:

في ضوء أهداف البر نامجج العامـة صيغت الأهداف الإجرائية للبر نامـج قى الجوانب الثلاثة (

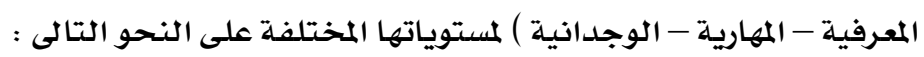
إهداف المعرفية : - الاهية

$$
\text { 1- ان يتعرف اللطفل على مفهوم النسيج المجسم · }
$$

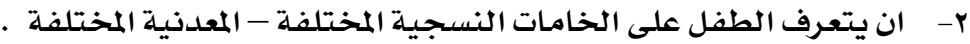

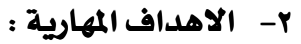

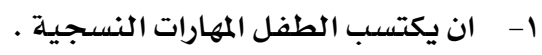

r- ان بتقن الطفل التشكيل بالاسلاك المعدنية .

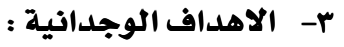

1- دعم مفهوم الذات و الثقة بالنفس من خلال ممارسة الإنتاج الفنى .

$$
\text { r- ت تحفيز العمل الجماعى و المشاركة مع زملائه . }
$$

r- التغلب على المشاكل النفسية المختلفة من خلال العمل الفنى

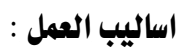

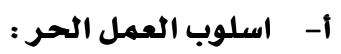

هو اسلوب غير مححدد حيث تترك الحريـة للآطفال لأختيـار الخامـات و الالوان ، و قـد تشارك

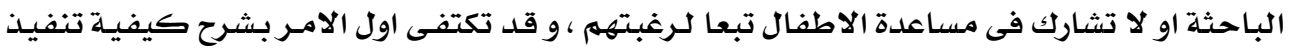

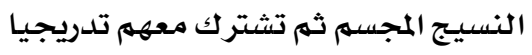

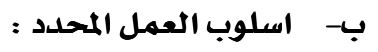

هو اسلوب محلدد و موجه و مخطط و فيه تحلدد الباحثة الادوات و الخامـات بهـا يتناسب مـع

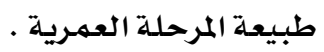


1- تناول التراث العلمى المرتبط بموضوع البحث ، لتحديد المفاهيم الاساسية والاطار النظرى .

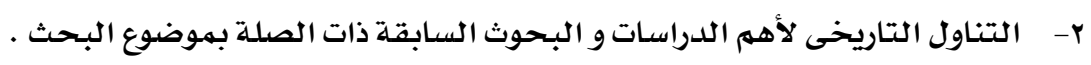

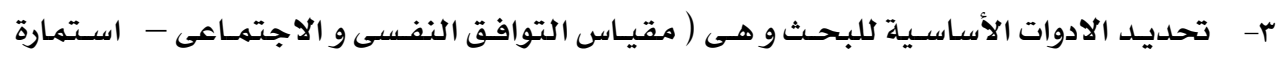

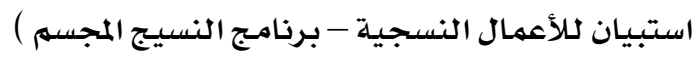

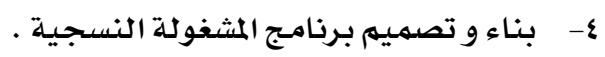

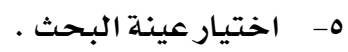

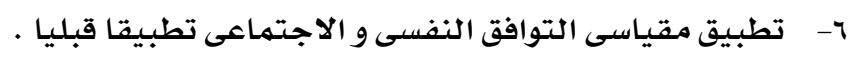

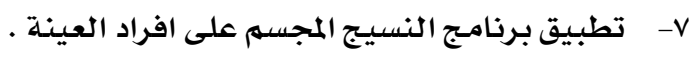

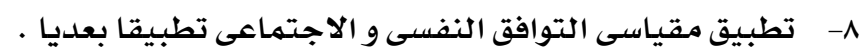
9- تحليل البيانات و عمل المعالجة الاحصائية المناسبة التى تتناسب مـع اهداف البحث و طبيعته . • - تفسير نتائج البحث فى ضوء الإطار النظرى و الدراسات و البحوث السابقة . 11- تقديم مجموعة من التوصيات المقترحة فى ضوء ما تسفر عنه من نتائج ·

علد الحالات (0 ) حالة الحالة ( 1 ) :

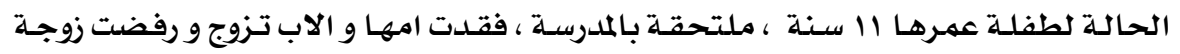

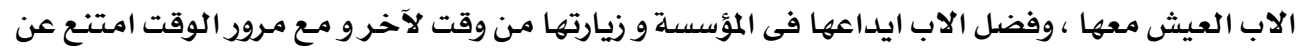

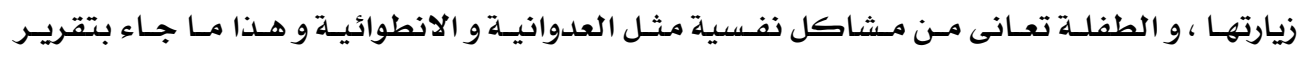

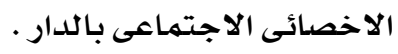

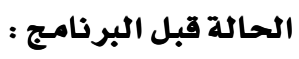

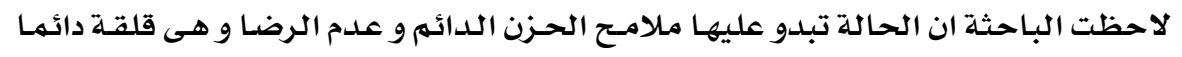

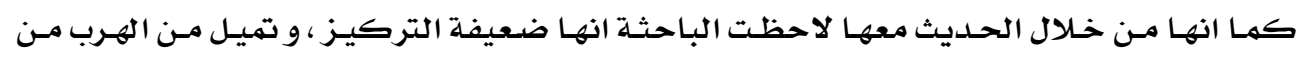

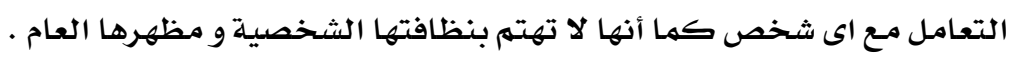

\section{الحالة بعد تطبيق البرناميج :}

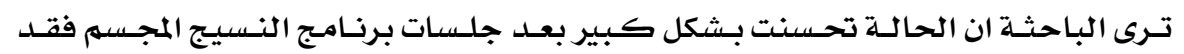

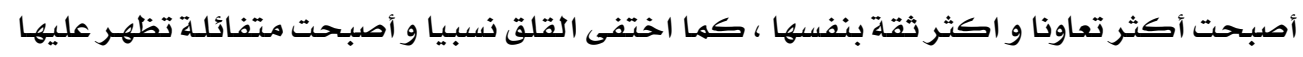

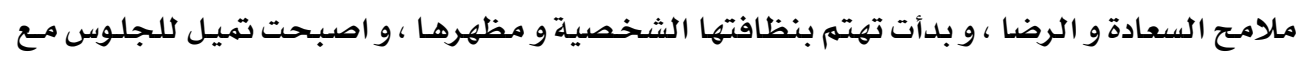

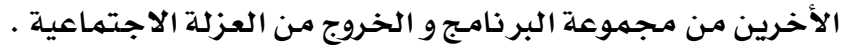


باكرغم من ان المثغولة النسجية المجسمة فردية الا انها تتم ممارستها فى إطار جماعى ، مما

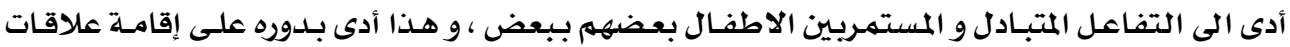

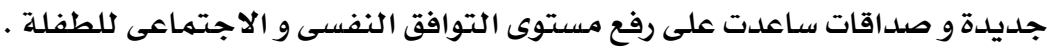

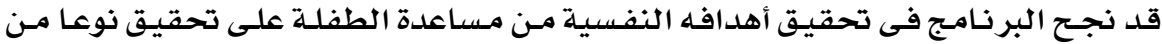

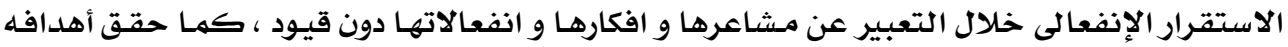

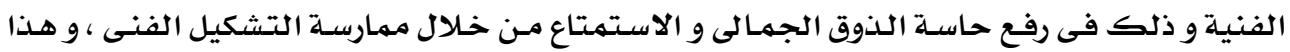

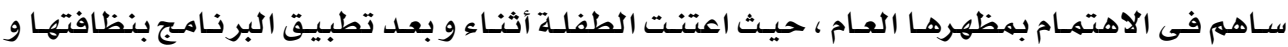

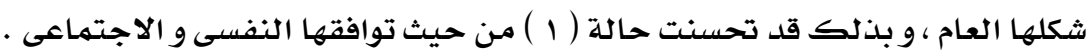
الحالة ( ) ( ) ( )

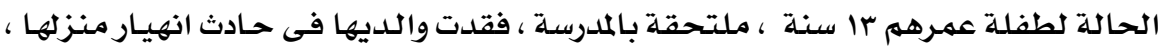
وفضل الاهل ايداعها فى المؤسسة ، و الطفلة تعانى من مشاكل نفسية مثل الانطوائية و عدم القـدرة

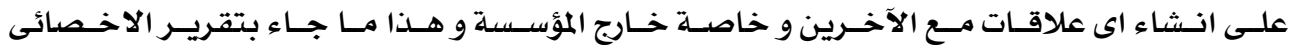

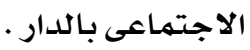

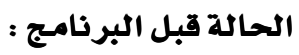

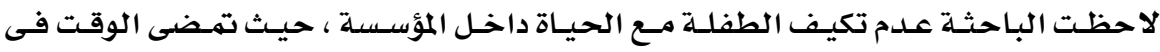

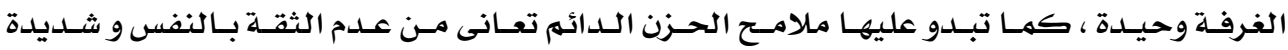

\section{الحالة بعد تطبيق البرنامهج :}

اكتشفت الباحثة ان الحالة كانت تمارس الاعمال الفنية من قبل و ذلك خلال الجلسات ،

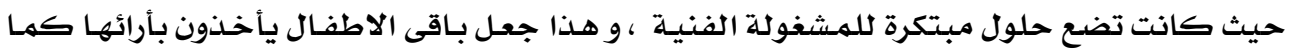

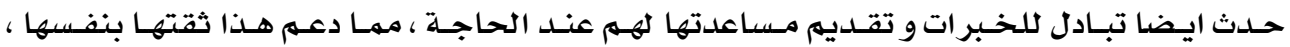

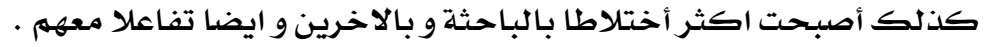

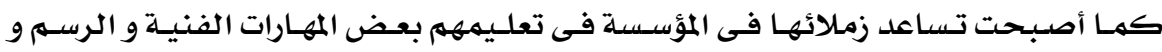

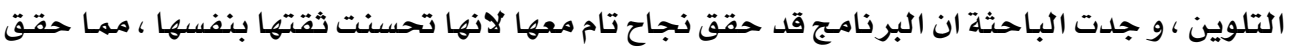

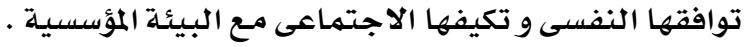
الحالة ( ) )

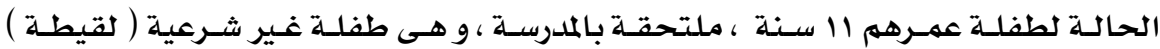

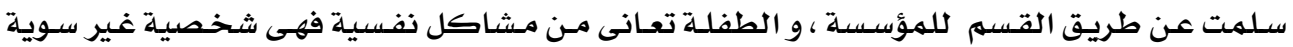

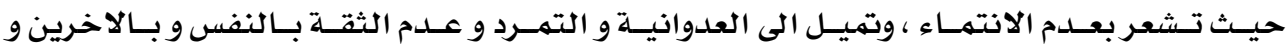




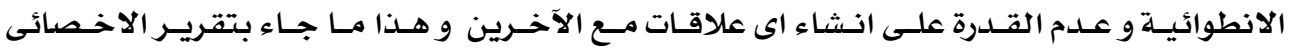

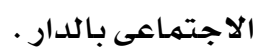

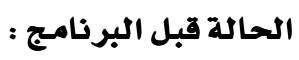

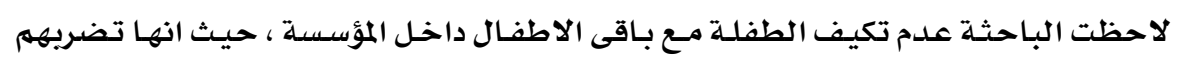

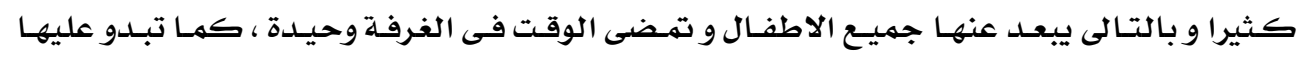

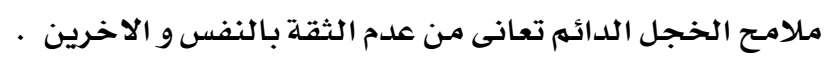

\section{الحالة بعد تطبيق البرنامج :}

لاحظت الباحثة اصرار الطفلة عدم تقبل البرنامـج المطبق و محاولة التزمـر الدائمر و و دائمـا

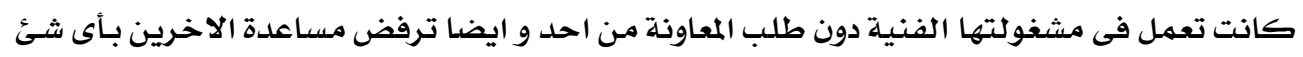

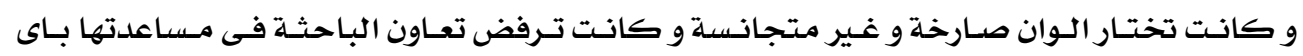

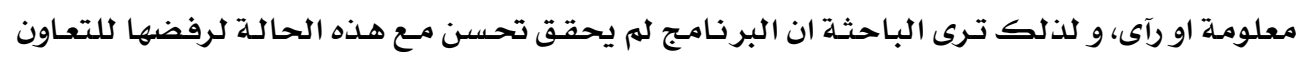

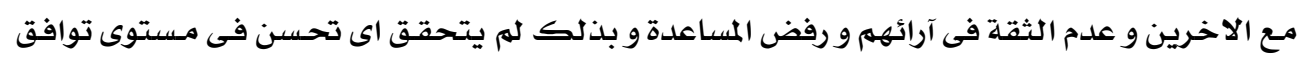

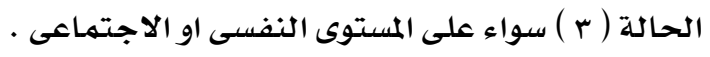

$$
\text { الحالة ( } 1 \text { ( - }
$$

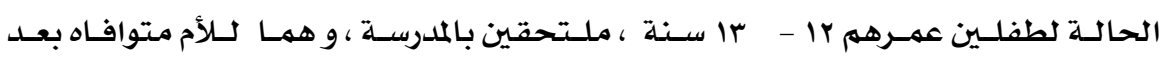

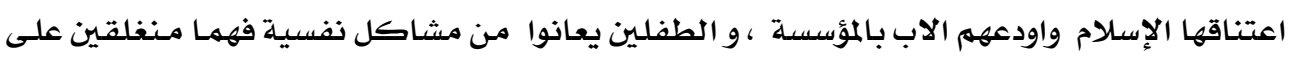

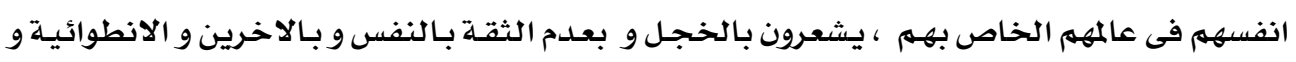

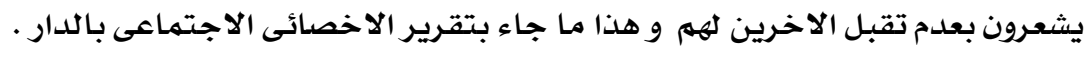

$$
\text { الحالة قبل البرنامج : }
$$

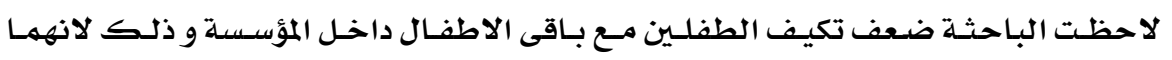

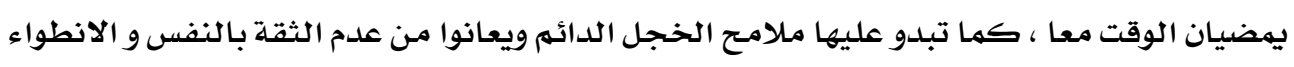

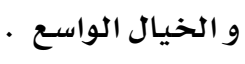

$$
\text { الحالة بعد تطبيق البرنامج : }
$$

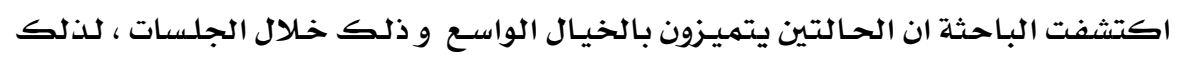

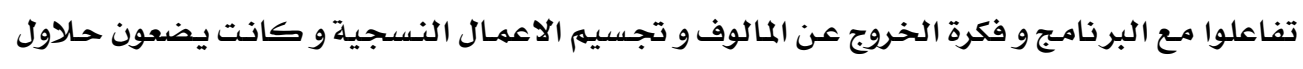

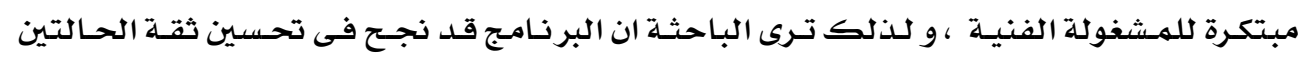

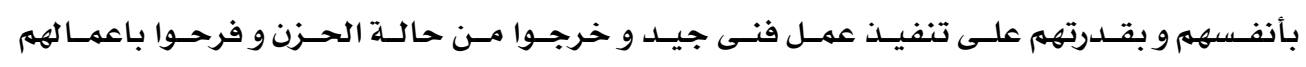
النسجية المجسمهة . 


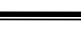

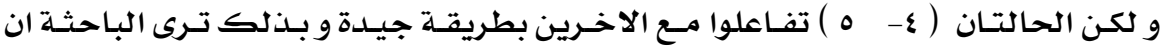

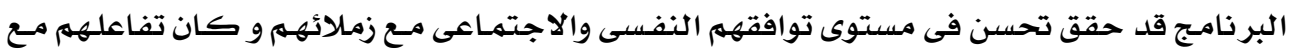
الباحثة جيد البراد

لذلك ترى الباحثة ان هاتان الحالتان قد تحقيق تحسن فى توافقهم الاجتماعى و النفسى.

عرض و توصيف المشغولات النسجية المسبمة :
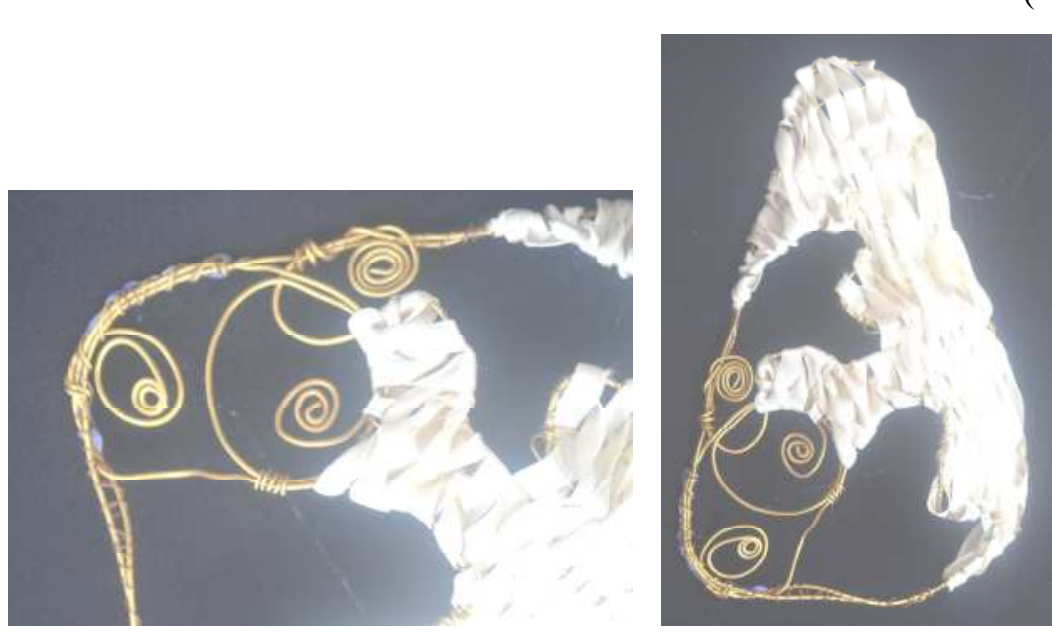

العمل رقم (1) - (1) - (1)

الوصف الفنى :

$$
\text { ا- اسم العمل : قطرة ندى }
$$

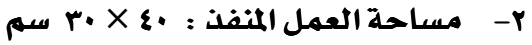

r- نوع السداء : أسلاكك نحاس اصفر ا مهم

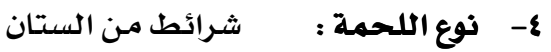

ه- الالوان المستخدمة فى العمل : أبيض

7- الخخامـات المستخدمة : شرائط الستان ا سهم - أسلاك معدنية 1,0 مهم

م التوصسيف الفنى :

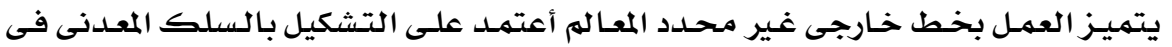

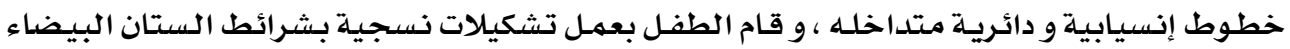

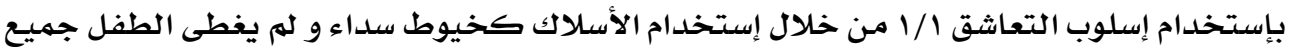
أجزاء التشكيل بينما ترك بعضها ليعبر عن الصياغات المعدنية التى قام بها . 

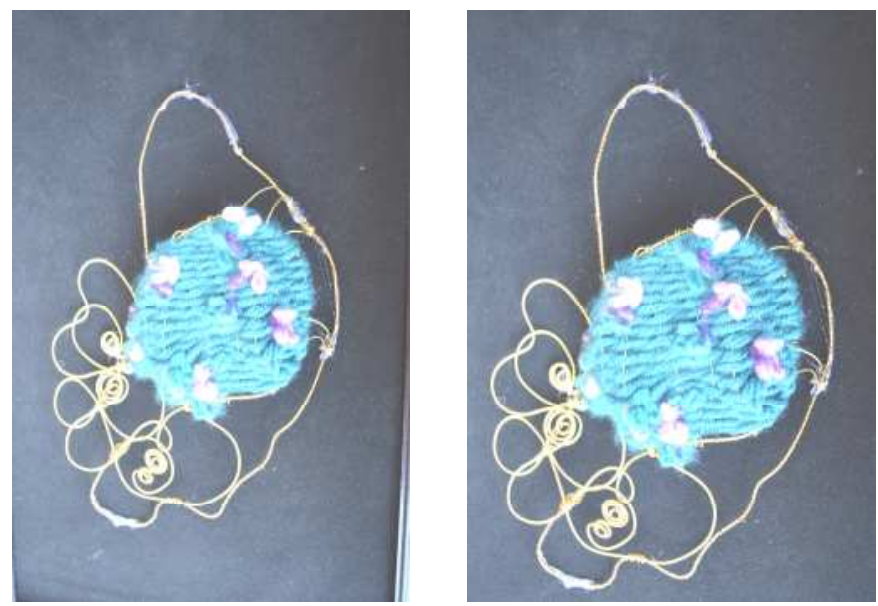

الوصف الفنى :

ا- اسم العمل : ديناميكية الفراشة

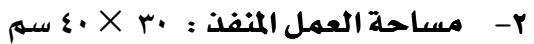
r- نوع السلداء : اسلاك من النحاس الاصفر ع- نوع اللحمة : خيوط صوفية زخرفية 0- الالوان المستخدمة فى العمل : الازرق الغامق - البنفسجى بلدرجاته 7- الخامات المستخلدمة : خيوط صوفية زخرفية - اسلاكك من النحاس الاصفر • ب التوصيف الفنى :

يتميز العمل بخط خارجى شبـه منتظم يشبـه جناح الفراشة أعتمـد على التشكيل بالسلك

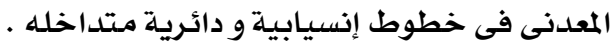

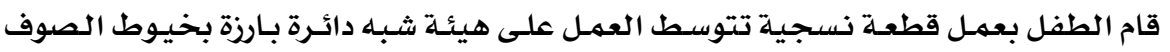

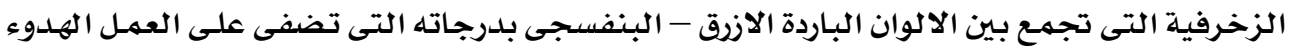

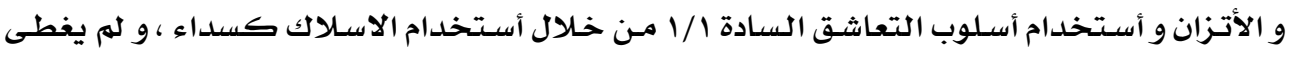

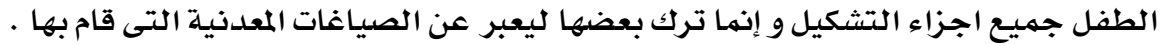
التشكيل فى مجمله عبر عنه الطفل عن الفراشة و التشكيل يتسمه بالانتظام و الدقة 

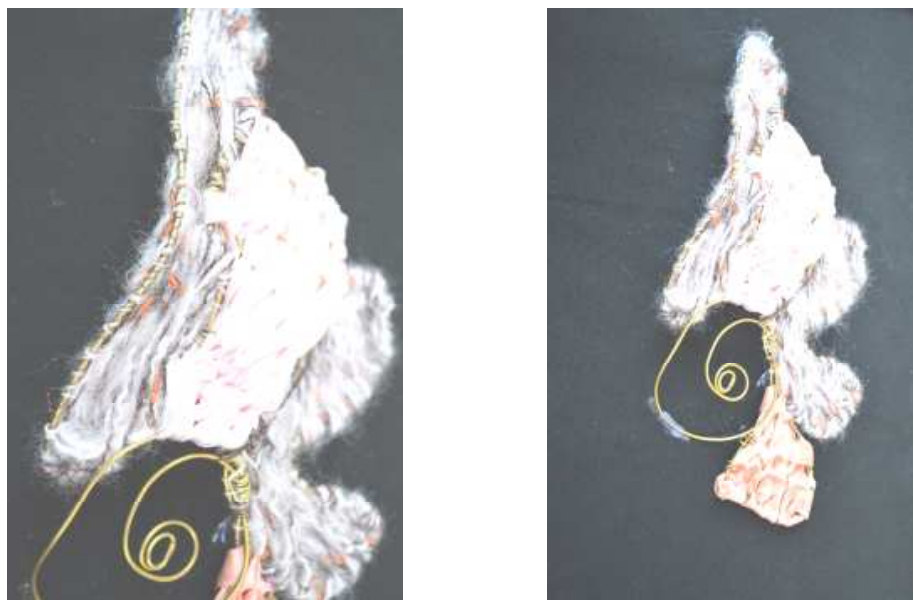

الوصف الفنى :

ا- ا- اسم العمل : رومانسية

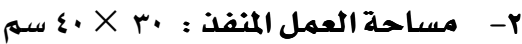

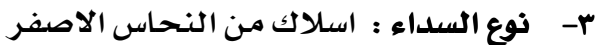
ع- نوع اللحمة : شرائط ستان - خيوط صوف زخرفية . ه- الالوان المستخدمة فى العمل : البرتقالى - البمبى - خيوط زخرفية ( رمادى - بنى - برتقالى ) 7- الخامات المستخدمة : شرائط ستان - خيوط صوف زخرفية - اسلاك من النحاس الاصفر ه التوصيف الفنى : 20

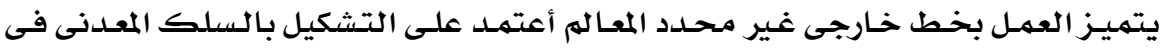

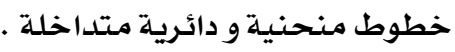
قام الطفل بتشكيلات نسجية بشرائط الستان باللونين البمبـى الفـاتح و البرتقـالى الفـاتح و

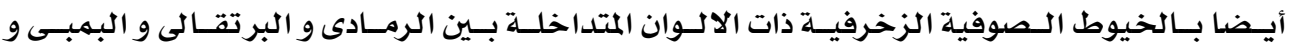

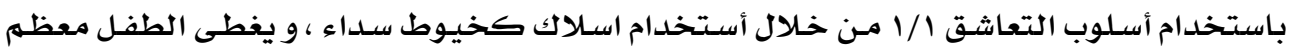

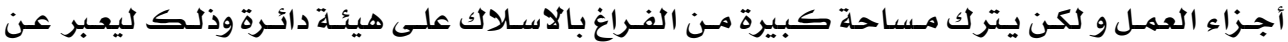
الصياغات المعدنية . الجزاء العهل و الشكل فى مجمله يتميز بالبساطة و الاتزان بين الكتلة النسجية و الفراغ . 

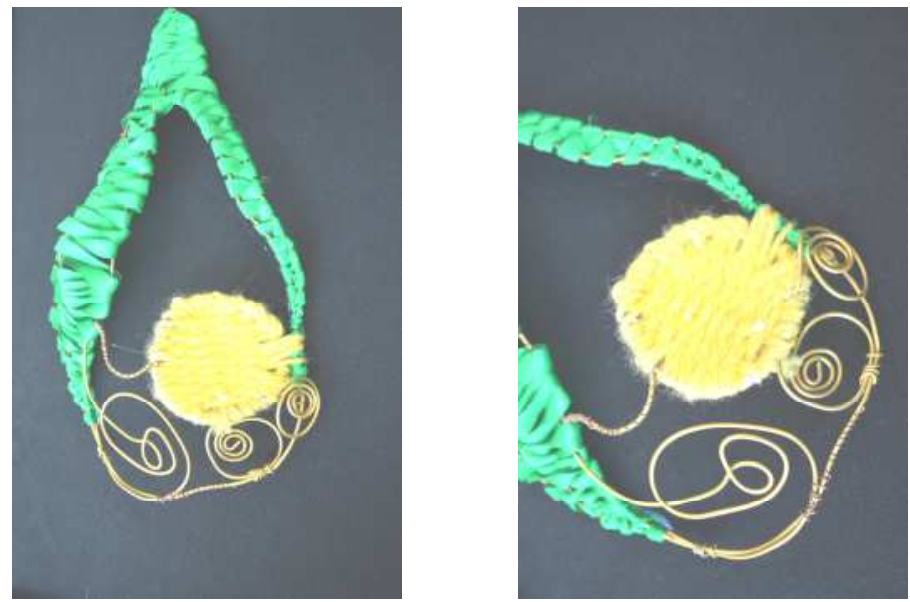

الوصف الفنى : ا- اسم العمل : ورقة الليمون

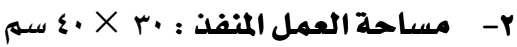
r- نوع السداء : اسلاك نحاس اصفر - خيوط من الفزل ع- نوع اللحمة : خيوط صوف - شرائط ستان ه- الالوان المستخدمة فى العمل : الاخضر - الاصفر r- الخامات المستخدمة : خيوط صوف - شرائط ستان - اسلاك نحاس اصفر - خيوط من الغزل \& م التوصيف الفنى :

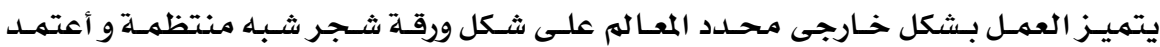

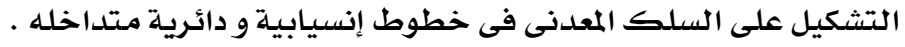

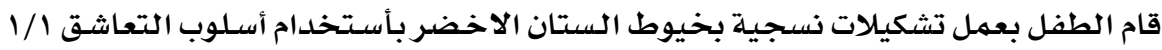

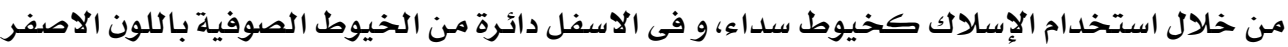

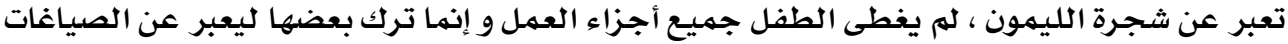

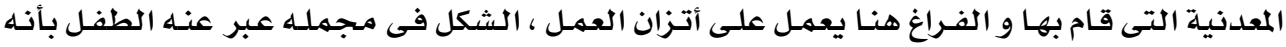

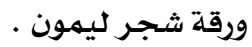



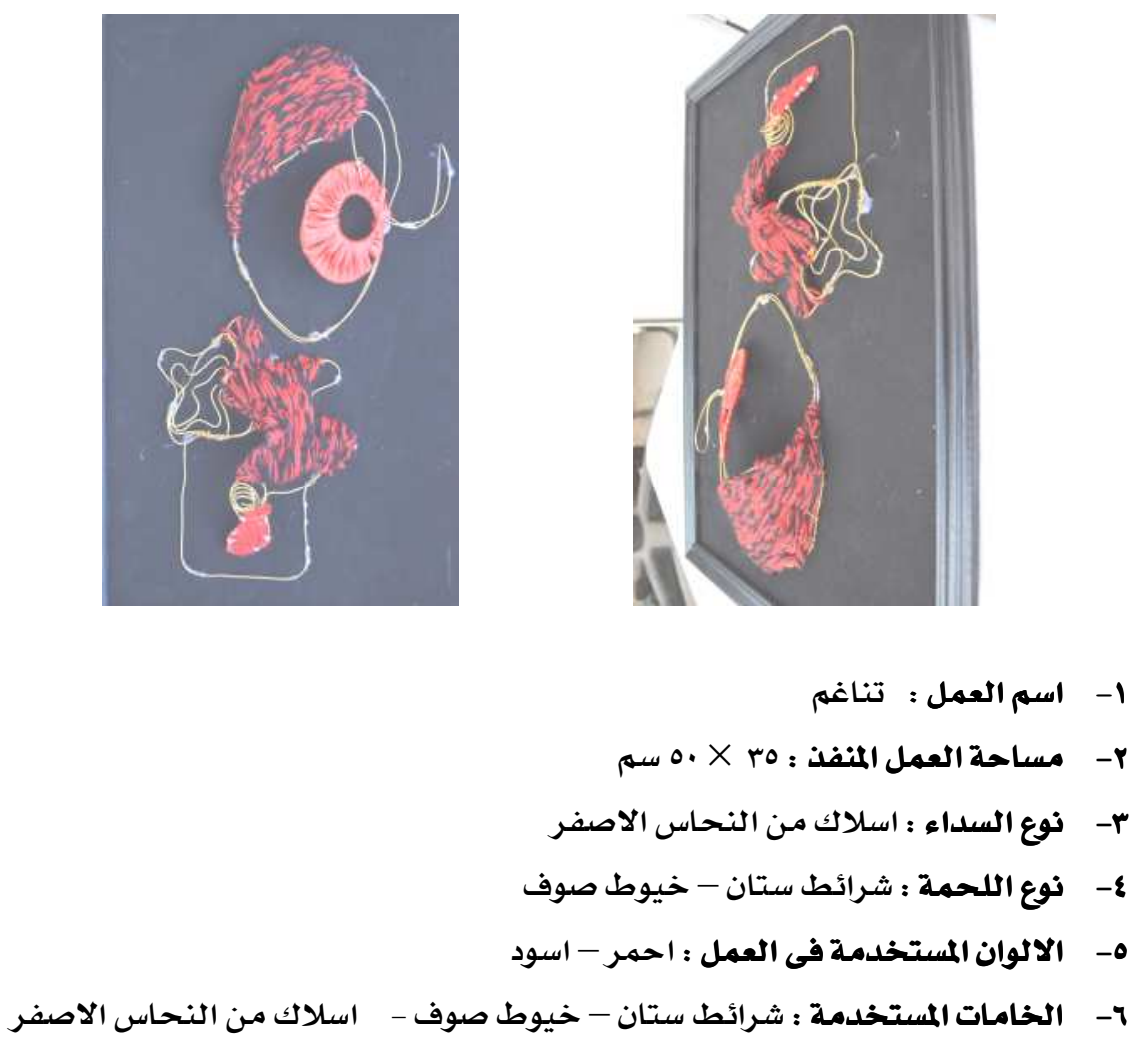

: م التوصيف الفنى :

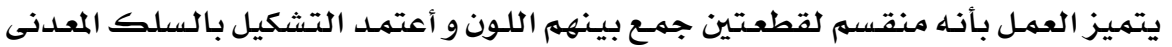

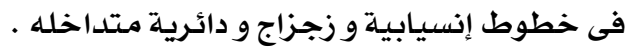

القطعة الاولى : شبـه بيضاوية جمعت فى التشكيل النسجى بـين استخلدام خاصسة شـرائط

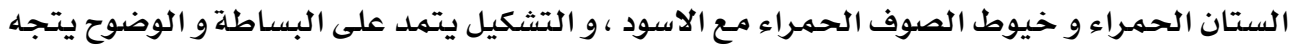

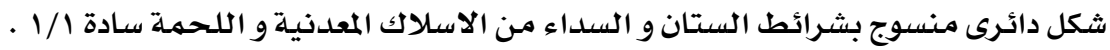

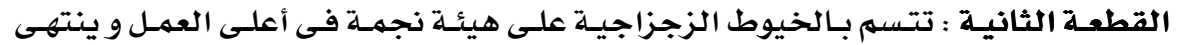

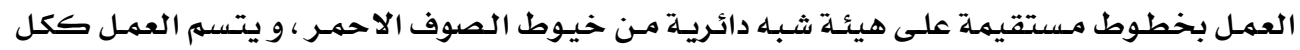

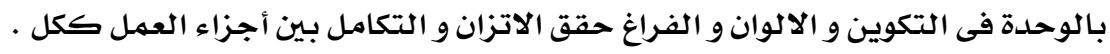


استسمارة تهكيم المشفولة النسمبية المسمسمة

\begin{tabular}{|c|c|c|c|c|c|c|c|}
\hline ملاحظات & امتياز & جيد جدا & جيد & 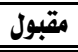 & ضعيف & بنود التقييي & الرقم \\
\hline & & & & & & اسلمس التصور الاول : التصرة و توظيف عناصر و & (i) \\
\hline & & & & & & الى اى ملى تحقيق اسس التصميه ؟ & 1 \\
\hline & & & & & & العمل ككل ؟ تحقيق الوحدة بين أجزاء & $r$ \\
\hline & & & & & & 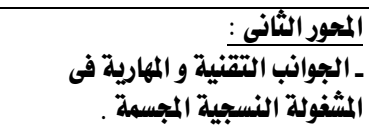 & (ب (ب) ( ) \\
\hline & & & & & & الاساليب النسجية ؟ تحقيق قيم بين الخامات و & $r$ \\
\hline & & & & & & الجمالى للمشفولة ؟ الإثراء التقنى و & $\xi$ \\
\hline & & & & & & ـ تحقيق التجسييم & (ج) \\
\hline & & & & & & ــ هل تحقية التجسيه فى المشفولة & 0 \\
\hline
\end{tabular}

اـ الفرض الاول

يوجد فروض ذات دلاله إحصائية فى متوسط رتب درجـات مقيـاس التوافق النفسى لاطفـال

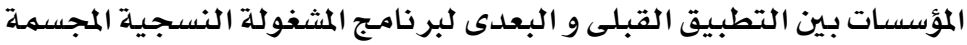

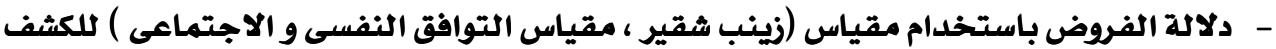

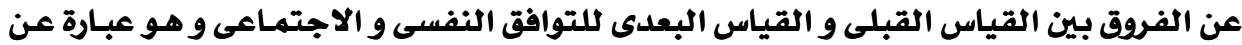

1..

و للتحقق من صحة هذا الفرض قامت الباحثة بما يلى :

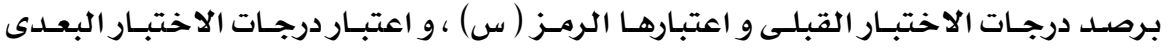

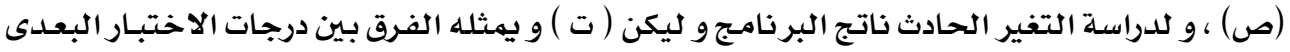

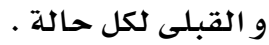

مقدار التغير = درجة الاختبار البعدى - درجة الاختبار القبلى

$$
\text { ت = ص - س }
$$

و الجدول التالى يوضـح تلك النتائج : 


\begin{tabular}{|c|c|c|c|c|}
\hline نسبة التحسن & (ص - س ) & ص & س س & رقم الحالة \\
\hline$\%$ & r. & vo & $\Delta 0$ & 1 \\
\hline$\div 20$ & r. & A. & 7. & $r$ \\
\hline$\div 7$ & $\checkmark$ & 89 & or & $r$ \\
\hline$\div 25$ & ro & 9. & 70 & $\xi$ \\
\hline$\div 27$ & $r V$ & $9 r$ & 70 & 0 \\
\hline
\end{tabular}

جدول (1) يوجد مقدار التغير الذى طراء على اطفال المؤسسات فبل و بعدبرنامج النسيج المجسم

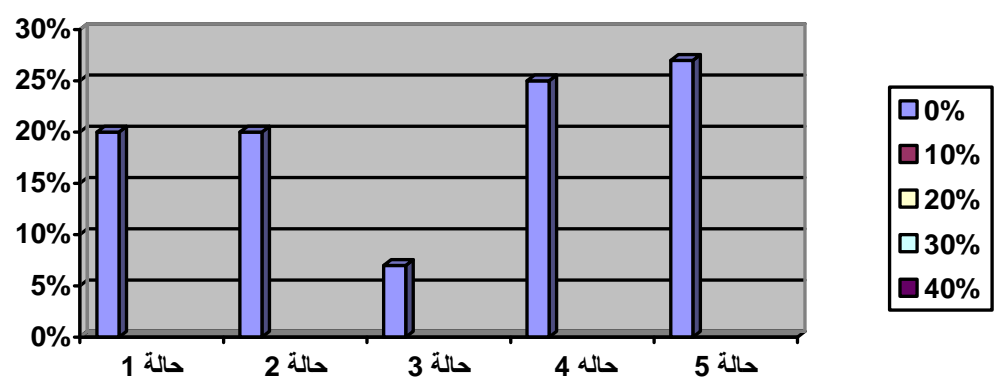

شكل (1) رسم بيانى يوضح مقدار تحسن اطفال المؤسسات بعد برنامج البحث

اذن قد تحقق الفرض الاول بانه يوجد تحسن فى مستوى التوافق النفسى لاطفال المؤسسات

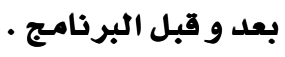

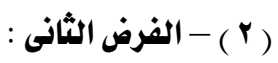

يوجد دلالاله احصائية في متوسط رتب درجات مقياس الاعمال النسجية المجسمـة لاطفـال

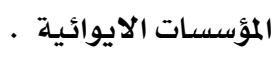

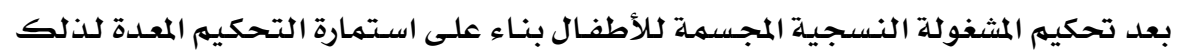

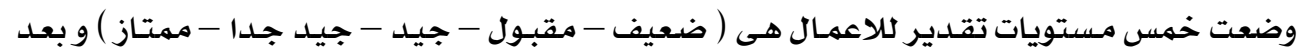

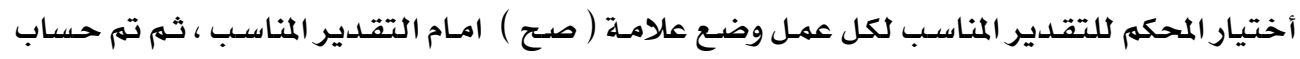

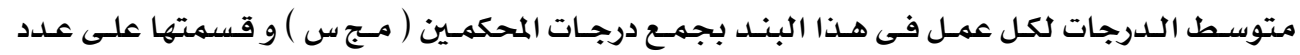

المحكمين ( ن ) ) متوس الـات

المتوسط = محيموع الدرحات

عدد المحكمهين

\section{م = م-ج}

ن 
ثم الحصول على النسبـة المئويـة بتحويله لتقدير عام عن طريق القانون

$$
\text { التقدير العام = نتبـحة المتوسط × × عدد الخانات التقدير }
$$

الجداول التالية توضتح النتائج الخاصة ببنود استمارة تقيم المشغولة النسجية المجسمة :

\begin{tabular}{|c|c|c|c|c|}
\hline مهتاز & جيلد جلا & جيد & مقبول & ضعيف \\
\hline 10 & 1. & - & - & - \\
\hline
\end{tabular}

$$
\text { يوضتح الجدول التالى النتائج الخاصـة بالبند الاول : }
$$

\begin{tabular}{|c|c|c|c|c|}
\hline مهتاز & جيد جلا & جيد & مقبول & ضعيف \\
\hline 18 & 11 & - & • & • \\
\hline
\end{tabular}

الجدول (r) يوضح النتائج الخاصة بالبند الاول

يوضتح الجدول التالى النتائج الخاصدة بـالبند الثانى :

\begin{tabular}{|c|c|c|c|c|}
\hline ممتاز & جيل جلدا & جيد & مقبول & ضعيف \\
\hline $1 \xi$ & 11 & - & - & - \\
\hline
\end{tabular}

الجدول (r) يوضح النتائج الخاصة بالبند الثانى

يوضتح الجدول التالى النتائج الخاصلة بـالبـند الثالث :

\begin{tabular}{|c|c|c|c|c|}
\hline مهتاز & جيد جلدا & جيد & مقبول & ضعيف \\
\hline IT & Ir & - & • & - \\
\hline
\end{tabular}

الجدول (ع ) يوضح النتائج الخاصة بالبند الثالث

يوضتح الجدول التالى النتائج الخاصدة بـالبند الرابع :

\begin{tabular}{|c|c|c|c|c|}
\hline ممتاز & جيد جلا & جيد & مقبول & ضعيف \\
\hline$\wedge$ & IV & - & - & - \\
\hline
\end{tabular}

$$
\text { الجدول (0) يوضح النتائج الخاصة بالبند الرابع }
$$

يوضتح الجدول التالى النتاكُج الخاصلة بـالبند الخامس :

الجدول (7) يوضبح النتائج الخاصة بالبند الخامس 


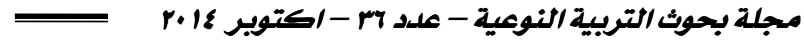

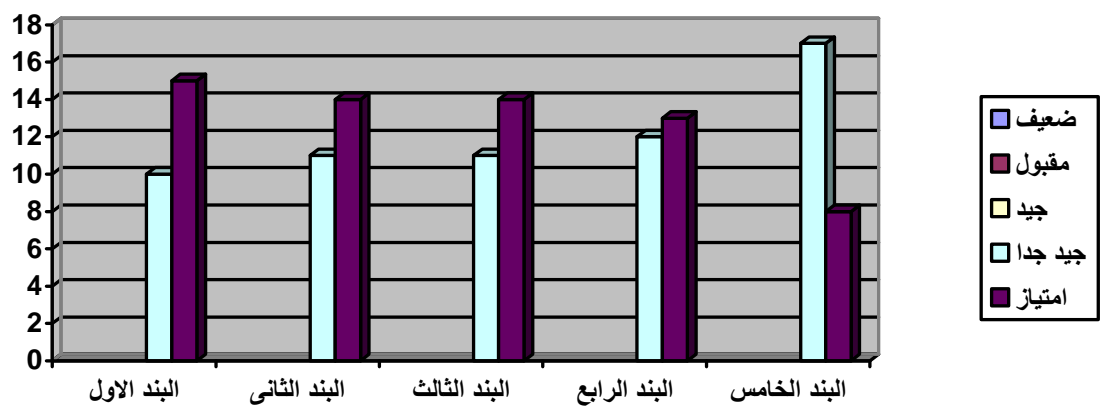

شكل ( r ) رسم بيانى يوضح تقديرات بنود استمارة تحكيم المشغولة النسجية المجسمة

و يتضح من الاحصاء الخاصة باستمارة تقييم المثغولة النسجية بأنه البندالخمس تحققت

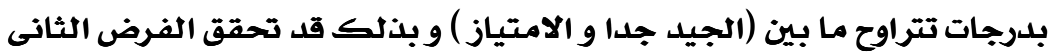

نتائج البمث :

ا- ان تحقيق تحسن فى مستوى التوافق النفسى والاجتماعى يرتبط بقدرة الطفل على التفاعل و

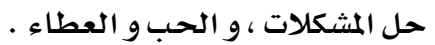

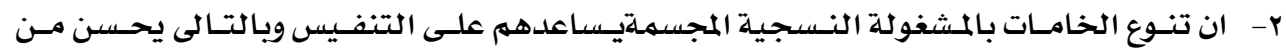

توافقهم النفسى والاجتهماعى .

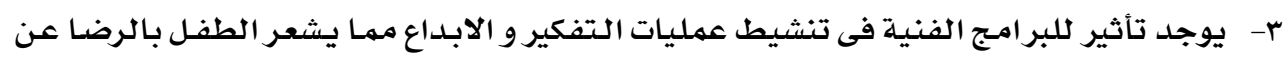

النفس و يحسن من توافقه النفسى .

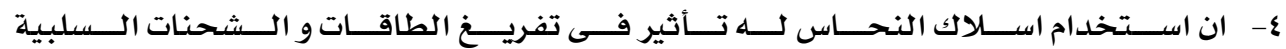
و الشعور بالايجابية.

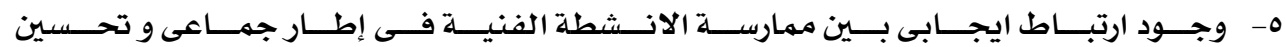

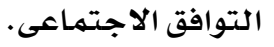

1- ان برناج النسيج المجسم له تأثير إيجابى فى دعم الثقة بالنفس و الأستقلال المادى والشعور بانـه

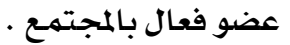


فى ضوء النتائج التى توصل اليها هذا البحث ، و التى كشفت عن فاعليـة البرنامـج المقترح

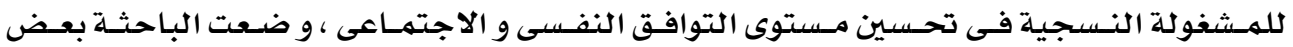

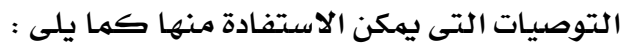
1- انشاء مـراكز فنية متخصصدة لأطفال المؤسسات لممارسة الأنشطة الفنية و شغل أوقات فراغهم و

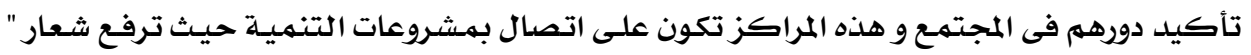

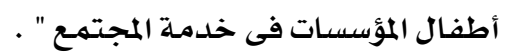

r- العمل على تصميهم عدة برامج فنية متنوعة لتعليهم أطفال المؤسسات المهارات الفنية المختلفة .

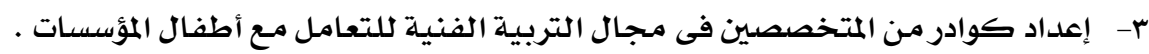

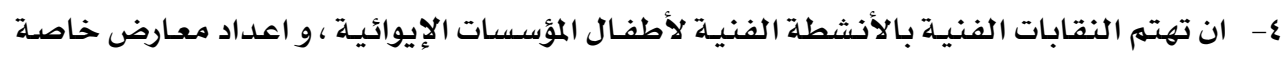

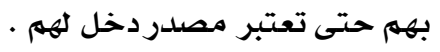
ه- ان تهتم الكليات الفنية بتدريس سيكولوجية اطفال المؤسسات لدى الطلاب .

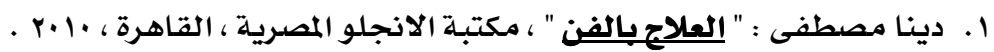

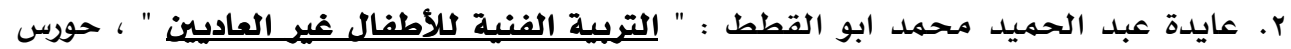

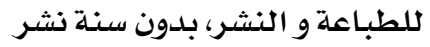

\section{ثانياً: الرسائل العلمية :}

1. أمنية عطا مقبل: " فاعلية برنامج لتنمية الذكاء الوجدانى لدى أطفال المؤسسات الإيوائية و

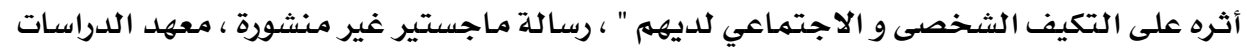

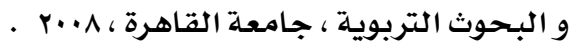

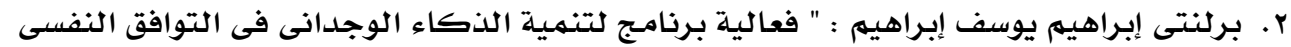

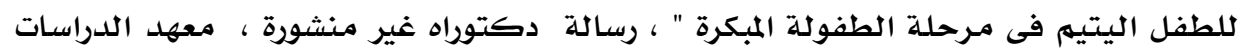

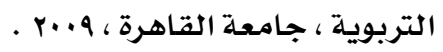

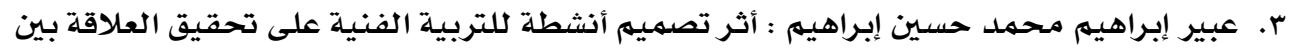

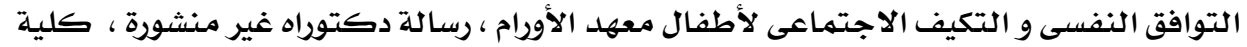

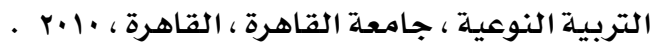

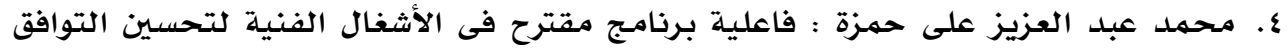

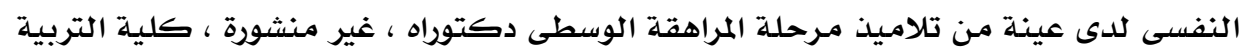

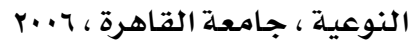




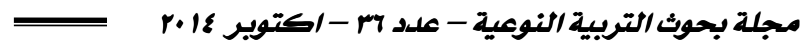

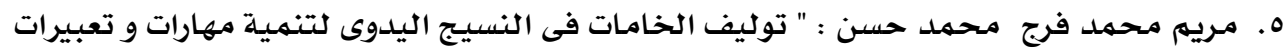

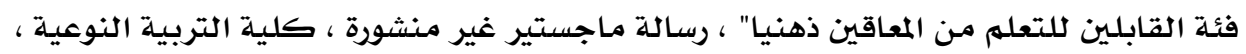

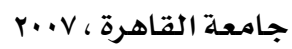

T. هبة رمضان عبد الحميد محمد الشوشانى : " الهندسة الفراغية كمداهدل لإثراء التهاء التشكيل

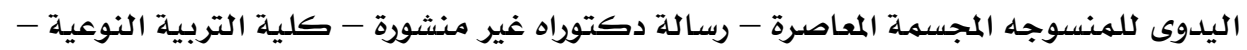

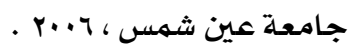

ثاثثاً : المجلات العلمية :

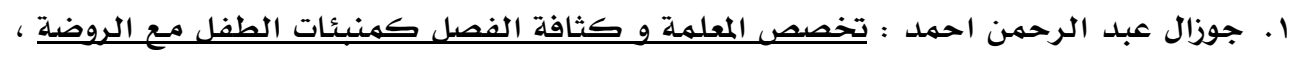

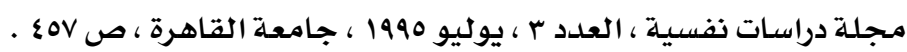

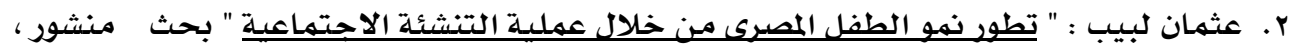

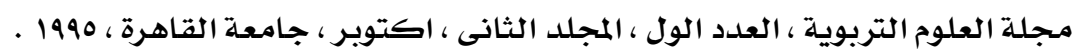

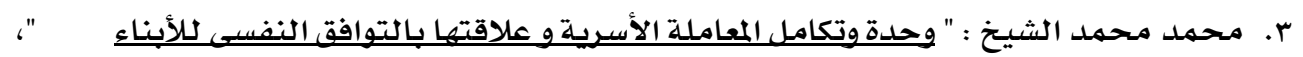

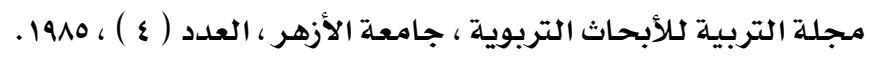




\section{Research Summary}

Arts practice is the process of helping the individual to discover and understand and analyze the same problems and the personal and emotional, behavioral and which may lead to poor compatibility of psychological and social problems and work to achieve a better level of psychological and social compatibility.

The most important thing to him is aimed at the study of the individual's personality so that he can guide his life the best way possible.

The fabric of the arts that helps a lot of different mental processes that help children with poor psychological and social compatibility on their improvement.

And from here you see the importance of building a researcher technician program to employ fabric in the life of children institutions in order to help them improve their agreement psychological, social, and by institutions Acquisition kids some skills and technical skills, and psychological, social, and cognitive.

The impact of the program busy textile holograms to improve the level of psychological adjustment and social Children lodging institutions have a positive effect, and this is where it is based on methods of textile techniques and metal simple and easy to fit with the nature of the children in the age group of 9-14 years to produce a busy textile stereoscopic.

The program has encouraged children to institutions to be active members of society enjoy the feelings of positive affect and are affected including around them.

This is the first step in getting rid of the feeling of inferiority and helplessness and consider themselves to look positive.

Where there is no close relationship between the positive and the psychological and social compatibility.

Man is positive, which is always trying to better and which overcomes feelings of despair, frustration and bear the suffering and difficulties and also capable to stop the headwaters of the negative thoughts and disposal.

This is more in line with the same people and her land. 